Lo único que permanece es el cambio

Con esta cita de Heráclito presentamos el cuarto número existencia. Si la labor del arquitecto consiste en la transformación de la realidad a través del acto de construir, como mencioción de la realidad a través del acto de construir, como mencio-
na Manuel Gallego en la entrevista que encabeza el número, la máxima aspiración de Palimpsesto es propiciar la reflexión de lector, arquitecto o estudiante, como condición necesaria para la transformación de su mirada y así "ver las posibilidades de la en su texto y que ha centrado el esfuerzo de los que produen su texto y que ha centrado el esfuerzo de los que produ-
cimos esta publicación con la propuesta de sumarios amplios y variados a la vez que tramados en lo oculto de su planteamiento. Cuatro números que nos permiten vislumbrar lecturas transversales, diálogos entre los entrevistados o réplicas entre
las reflexiones sobre la enseñanza de la arquitectura, buceando las reflexiones sobre la enseñanza de la arquitectura, buce
en un amplio abanico de visiones de lo arquitectónico.

Al tiempo de tribulaciones que vivimos proponemos, por pequeña que fuere, una mudanza intelectual que en este numero tien una maravillosa encarnación en la propuesta para el museo de antiguo molino en un museo integrado en el pueblo y también, en la naturaleza que lo rodea. El interés de su proceso de construcción trasciende lo material para hablarnos de su integración sociológica. Paisaje y sociedad son los dos ingredientes que mos recogidos desde ópticas diversas en otras aportaciones de mos recogidos desde ópticas diversas en otras aportaciones de le la construcción de la casa Farnsworth, la compleja relación de la construcción de la casa Farnsworth, la compleja relación
entre Mies y la señora Farnsworth o entre su concepto de paisaje y el uso real de la propietaria. A otra escala y desde otro enfoque contrapuesto al narrativo, Ignacio Díez Torrijos, realiza una
rigurosa disección del territorio que dio sentido al nacimiento de rigurosa disección del territorio que dio sentido al nacimiento de la ciudad de Valencia, su riquisima huerta donde el agua es su profundo del territorio y su evolución, sino que ofrece elementos profundo del territorio y su evolucion, sino que ofrece elementos está sufriendo la Huerta de Valencia.

El agua es también protagonista en el paisaje del archipiélago canario, ya sea por su presencia real como latente. A traves de irrigan de forma novedosa su territorio y que van a ser el tema de reflexión de los equipos de arquitectos y paisajistas invitados al workshop internacional 7×1000millas. Reaparece así en $\mathrm{Pa}$ limpsesto el tema del viaje, recurrente por su forma de generar un viaje a Japón a través de las resonancias culturales y arquitectónicas que le sugiere la visita de un grupo de arquitectos ca-
talanes invitados para exponer su trabajo, bajo la denominación talanes invitados para expone
de "Arquitectura es paisaje".

La rotundidad de esta afirmación dialoga con la sutileza y multiplicidad de lecturas que ofrece el texto de Ricardo Devesa en sus cinco maneras distintas de abordar la relación entre naturaleza y arte, a través de otras tantas escenas cinematográficas
entorno a un árbol. En una de ellas "El árbol, como el río, es una entorno a un árbol. En una de ellas "El árbol, como el río, es una un flujo en continuo cambio, aunque asimismo, en constante reun flujo en continuo cambio, aunque asimismo, en constante re-
petición". Y así con esta recurrencia sobre las estructuras que permanecen y a la vez cambian, nos permitimos interrogarnos sobra la validez hoy de las palabras de Josep Quetglas sobre la organizado por la cátedra Blanca hace ya seis años y que recogemos en la contra de este número 4. Unas palabras llenas de provocación que nos invitan a reflexionar sobre la esencia del
aprendizaje de la arquitectura pero también sobre su irremediable descenso a los infiernos $(i)$ de la realidad.

Viaje y transformación, dos conceptos tan ligados al tiempo y a la memoria, acuñados en esta primavera del 2012 por dos reno Mansilla y Manuel Solà-Morales a quienes van dedicadas cada una de las líneas de este número.

LA PERMANENCIA DEL CAMBIO

\section{En memoria}

Extracto de Apuntes de viaje al interior de tiempo, Fundación Caja de Arquitectos, Colección Arquithesis 8

Alrededor de unas ruinas y unos paisajes italianos casi siempre inmutables, observando las notas, fotografias y apuntes que deja el rastro del viaje, la contiguidad de las imágenes intenta imaginar como las distintas formas en que algunos arquitectos representan lo que nos rodea so una declaración de intenciones sobre su posiLa materia es inerte y muda, pero al arañarla, a La materia es inerte y muda, pero al arañarla, a
rozar con la vida, al cambiarla de sitio, ya no sólo muestra lo que es, sino también lo que quisiera ser, su vocación y sus afanes. Una vocación que necesariamente expresa (y oculta) un entendimiento del mundo. Un entendimiento que puede ser visto casi en términos físicos... Frente a la testaruda determinación de la naturaleza, hombre y la mujer se sublevan a la búsqued de un espacio mental propio, presidido por libertad: libertad para situarse ante un mund (imaginando que puede ser modificado) y una cultura (imaginando que puede ser entendido). Un espacio, pues, animado por el potencial de las cosas, como si en nuestro modo de yacer en el mundo pudieramos reivindicar lo posible, aquello que puede ser hecho, frente al sentmiento que nos transmite la lejanía de la vida.

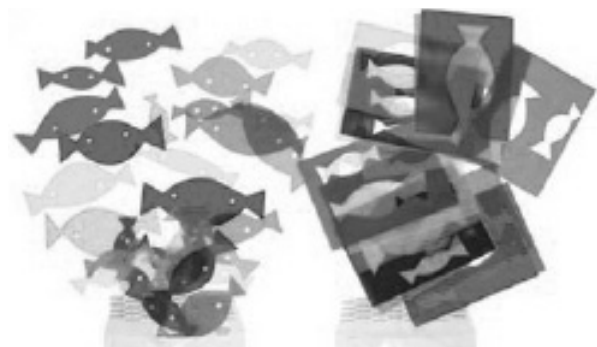

Dibujo de Luis Moreno Mansilla y Emilio Tunón para Scalae

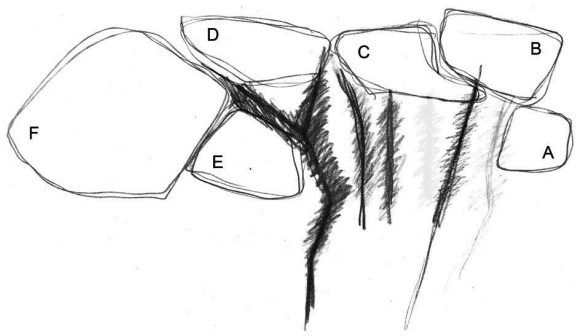

Dibujo de Manuel de Solà-Morales para el Prat Nord

Extracto de el texto de presentación como comi-
sario de la exposición Ciudades, esquinas Manuel de Solà-Morales (1939 - 2012)

Cuando me pidieron realizar una exposición acerca de las ciudades, inmediatamente pense que no era cuestión de insistir en una muestra tópica de los "problemas" urbanos -infraestructuras, vivienda, periferias, renovación, etc. -que hablase, por ejemplo, de flujos, mutaciones, reflejos o márgenes-, sino que pensé en presentar las ciudades a través de algo muy concreto, material y tangible, algo que valorase más los sentidos que la abstracc

Pensé entonces en el interés figurativo de las esquinas, y en la condición de la esquina como paradigma de la diversidad urbana, arquitectó

La diversidad cultural es un hecho urbano. En el mundo contemporáneo, donde más del $80 \%$ de la población vive urbanizada (y el resto no puede tardar en asimilarse a ella como única garantía de su proceso económico y social), las ciudades son las máquinas fantásticas que permiten transformar la soledad en intercambio y la ignorancia en progreso.

Así pues, para presentar la diversidad cultura no es necesario imaginar un mosaico de exotismos, sino presentar las ciudades como el luger de mezcla e intercambio, lugar plural y contradictorio por excelencia, lejos de las reducciones
demasiado simplistas o sistemáticas que hacemos a menudo. [...]

La ciudad, que ciertamente es un sistema complejo en continua transformación y también, en ocasiones, una concentración unánime participativa -de forma más o menos patrocinada-, es el lugar de la diferencia y la fricción, del acuerdo forzado o fortuito, de tensión y conflicto permanente. La intersección de personas, construcciones, movimientos y energías es la razón y la fuerza de la ciudad. Las esquinas son el modelo primigenio.

\section{Manuel Gallego}

Te agradecemos mucho la concesión de esta entrevista. En y que no es forzosamente bueno hacerlo. ¿No crees que hoy la Arquitectura tendría que volver a pedir la palabra?

No recuerdo exactamente cuándo ni cómo lo he dicho, pero sí, alguna vez me he referido a que a veces los arquitectos hablan más de lo que construyen, y a que la arquitectura no se sustituye ni su-
planta por la palabra con explicaciones añadidas. Otras veces ocurre que entre lo que se dice y lo que se hace sólo veo contradicciones y

Los textos importantes, los que a mí me lo han parecido, se preguntan sobre la arquitectura desde la necesidad personal de hacerla. Buscan explorar sobre cuestiones que necesita el autor para entenderla y hacerla. Así me ha parecido con autores tan dispares como Le Corbusier en Vers une architecture, A.Rossi en La arquitectura de la ciudad o Venturi en Contradicción y complejidad en la arquitectura.

Otras veces esto mismo se trasluce en textos cortos pero intensos sin estructurar en un libro. Todo esto me parece importante y me Me

entre ellos abundan además los retóricos.

Cuando decimos volver, nos referimos también a los años de tu formación tanto en Madrid como junto a un maestro como De la Sota, ¿ha cambiado tanto la arquitectura y su papel?

Ha cambiado varias veces en su apariencia. Han habido modas diversas, cada una con sus razones y excesos, no voy a entrar en ello. Pero basta recordar desde la primera postmodernidad salpicada de lenguaje historicista, hasta la exuberancia formal y la búsqueda
del espectáculo más reciente, y ahora nace la pretendida austeridad, traslación de la crisis en que estamos.

Cambios en la apariencia, pero yo creo que en el fondo cambia poco, y sin embargo han cambiado los instrumentos de información, la producción del proyecto y la tecnología de la construcción. Ha cambiado el papel del arquitecto en la sociedad, y ahora estamos en uno de esos momentos de incertidumbre que hace que nos preguntemos si no se está alumbrando una nueva profesión, y si todos estos que aun no ha tomado forma.

Me resisto a renunciar a la idea de que siempre se necesitará construir espacios para vivir mejor, resolver necesidades y satisfacer alguien que se emocione y que aporte su visión. Es decir un arquitecto.

Dejando un poco de lado la inmediatez de la coyuntura, queríamos preguntarte precisamente sobre ese retorno que hiciste a tu tierra. Parece que el equilibrio que trasluce tu arquitectura entre la formación universal y la atención por lo particular, es una consecuencia de tu propia biografía...

Volví a mi tierra por varias razones, una atraído por lo mío, otra apartándome del ruido que entonces me suponía Madrid.

El encuentro no fue fácil. Llegué a una periferia que era casi un desierto en la arquitectura, salvo en muy contadas excepciones. Pero la conexión intelectual ya era posible desde cualquier sitio, y además yo buscaba entender si lo que había aprendido y lo que me interesaba de la arquitectura era compatible con la vida, me interesaba su relación con ella y con un lugar concreto.

Sin saberlo intuía lo que hoy sé, que en cualquier lugar por pequeño que sea cabe el mundo entero.

Me costó trabajo y pasé una temporada en París con una beca L'ASTEF. Porque fijar la residencia era también algo más.

¿Cómo decidiste ser arquitecto?

No tenía claro lo que quería ser, me gustaban las ciencias y las letras, aquello que orientaba la profesión de los estudiantes. En un
viaje vi arquitectura que me llamó la atención y decidí probar. Naturalviaje vi arquitectura que me llamó la atención y decidí probar. Naturalmente no tenía ni idea de lo que era. Después en segundo año de la carrera siendo de la Sota profesor de proyectos me enseñó una casa que estaba haciendo en Pozuelo, creo que porque yo en un proyecto proponía algo que se parecía. Allí entendí la arquitectura y me reafirmé en la decisión.

En tu relación con de la Sota, David Cohn señala que colaboraste en su despacho en una de sus épocas más estrictas, en cuanto a medios y necesidades, generando una arquitectura casi invisible basada en la prefabricación y la industrialización. ¿Estás de acuerdo con ello? ¿Tu mirada retrospectiva al maestro ha cambiado con el tiempo? ¿Qué otras enseñanzas destacarías?

No sé si la palabra exacta es estricta. Pero creo que sí que se aproxima bastante. La arquitectura era invisible en la apariencia, huía de las formas preconcebidas y sobre todo de las más de moda, pero se llenaba de significados más profundos técnicos y conceptuales. Buscaba un cierto anonimato. Paradójicamente, a de la Sota se le conocía y creo que aun hoy se le

De la Sota era un hombre de una personalidad fuerte y muy compleja. En sus clases casi no enseñaba cosas concretas, sino actitudes, en cierto modo te preparaba para seguir aprendiendo. Así con el paso de los años confundes a veces lo que aprendiste directamente de él y lo que tú has añadido.

Mi relación con el fue más amplia; primero de profesor, luego como maestro y amigo, duró desde que le conocí hasta su muerte. Mi admiración y cariño no implicaba que estuviese de acuerdo en todo, como es natural.

¿Señalarías alguna otra referencia explícita en tu arquitectura?

De la Sota nos decía que una forma de aprender era ir observando lo que veíamos y cuando una arquitectura nos gustase, anotáde toda la arquitectura que me gusta, incluso de la que no me gusta, 
y también he aprendido a interesarme por el por qué más que por el cómo.

Con los años lo he extendido a la otra arquitectura, la que no hacen los arquitectos. Siento una especial atracción por aquellas que están al margen de la cultura oficial de la arquitectura, a veces me parecen más libres y con menos prejuicios que las más ortodoxas.

Por tanto el aprendizaje se ha convertido en tratar de entender por qué las cosas y las formas son como son cuando las veo. Una tarea que me entretiene y me ocupa.

Ha cambiado el papel del arquitecto en la sociedad, y ahora estamos en uno de esos momentos de incertidumbre que hace que nos preguntemos si no se está alumbrando una nueva profesión, y si todos estos cambios son forma de vivir que aún no ha tomado forma.

¿Podríamos decir que tu arquitectura, junto a cierta pureza en sus raíces modernas, ha bebido en algún momento de propuestas como las de la Tendenza, Scarpa o, sobre todo, Kahn?

Recuerdo la emoción que sentí la primera vez que vi una obra de Kahn, eran los Baños de Trenton, creo sin duda que esa obra de Kahn, eran los Baños de Trenton, creo sin duda que esa ciudad de Rossi y la visita al Galaratese. Pero su arquitectura, as como la de Scarpa, no creo que me haya influido.

Siempre me interesaron las ideas y la sequedad expresiva de los Smithsom, su estética me sorprendió. También me he sentido atraído por Escandinavia, su cultura y su paisaje. He aprendido y disfrutado de las arquitecturas de Aalto, Sirem, Asplund, Lewerentz etc... Viajé varias veces a Escandinavia y siendo alumno trabajé en el estudio de E. Viksjo, en Oslo.

¿Nos permites considerarte uno de los apóstoles que trajo la arquitectura moderna a Galicia? ¿Consideras que hoy de secuencia maestro-discípulo?

Creo que te equivocas.

Hace poco, y con motivo de una tesis, leía un discurso del arquitecto coruñés Santiago Rey Pedreira del año 1928, en él se cita el primer Congreso de los CIAM en La Sarraz, ocurrido hacía seis meses. Él introdujo la arquitectura moderna en A Coruña y en Galicia, otros le siguieron, pero la Guerra Civil produjo un profundo corte cultural y el olvido. En la posguerra, Bar Boo y Fernández Albalat recuperaron una arquitectura gallega actual.

Si existe esa continuidad debe ser que estoy tan próximo que no la veo. Creo que la relación entre un buen discípulo y su maestro parte de que cada uno debe conservar su persohalidad. Sus arquitecturas no tienen por qué parecerse en sus apariencias, puede ser que se parezcan en sus enfoques y actitudes. Esta proximidad de la que hablaba, y seguramente la despreocupación, me impide apreciar si existe eso que llamas secuencia maestro-discípulo. Seguramente serán otros los que puedan opinar con más razones.

En dos de tus últimos proyectos como son la piscina de Chantada o el centro de Salud de Viveiro, parece que tu papel como arquitecto trasciende al estricto proyecto, tu papel como arquitecto trasciende al estricto proyecto, sugiriendo emplazamientos e interactuando con la raiz del encargo en una acción, en el buen sentido de la palabra, casi política. ¿Es éste un te

Sería bueno que personas creativas, con sensibilidad e maginación, estuvieran en la política, sean arquitectos o no. imaginación, estuvieran en la política, sean arquitectos o no. Personalmente nunca he pretend

Lo que he pretendido es buscar y entender las razones de la necesidad de la arquitectura que me encargan, entender para qué es necesaria, si lo es. Cuando lo es, me parece que el proyecto se llena de fuerza, con independencia de la componente creativa, poética y personal que pueda existir, que naturalmente es fundamental.

Estas reflexiones me llevaron a pensar que el proyecto puede resolver más necesidades de las se derivan de sus programas inicialmente, y a pensar en él como un elemento capaz de generar cambios en el entorno, como una energía capaz de modificar y reorientar el proceso de cambio a que esta sometido. Esta vision conduce a otra más urbana o territorial del proyecto, ncluso en temas más reducidos y cotidianos, a establecer relaciones con lo que existe, y a pensar en cómo evoluciona o como

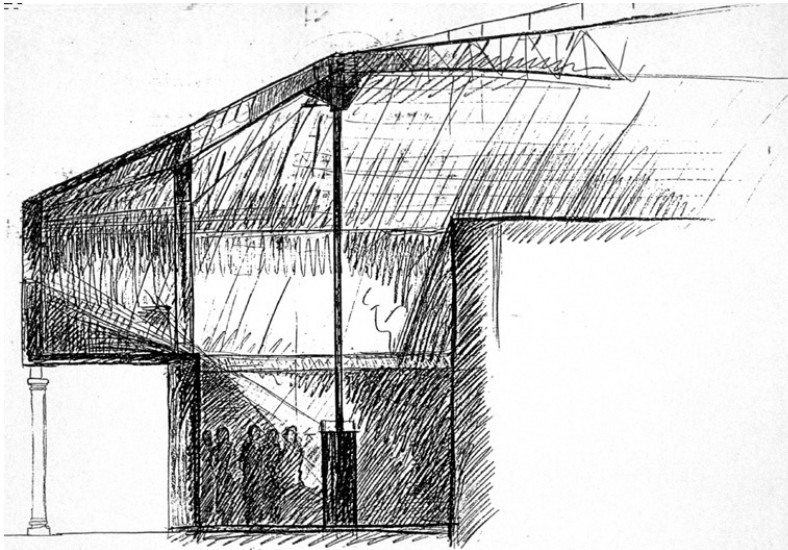

puede hacerlo con el edificio que se proyecta, el cual irremediaEsto me interesa porque me parece que lo hace más real. Sobre estos temas hice una pequeña exposición y desarrollé un curso en la Universidad de Munich.

En tu defensa del uso frente a la función, ¿podríamos imaginar al arquitecto como un creador de contenidos, un detector de oportunidades, un lector de la ciudad?

Creo que el arquitecto debe ver las posibilidades de las cosas, ahí está su lado creativo. Descubrir el potencial implícito en algo es imaginar lo que puede llegar a ser, lo que puede hacer que eso sea. Al imaginar, ya estás creando. Supongo que esto es generalizable a todas las actividades. Yo me refiero al arquitransformadora de una construcción para que lo mejore y la gente sea más feliz usándolo.

Esta actitud alerta para escuchar las posibilidades y sugerencias forma un complejo mundo que soporta la creación, sea plástica, formal o espacial. Todo es un conjunto que pretendemos hacer coherente. ¿Las intervenciones en la casa de la cultura de la Chantada se pueden interpretar en esta de Bell

Ambas obras las pensé como espacios públicos. Son edificios pensados como prolongación del espacio de la ciudad. Sería como si el espacio urbano se condensara creando un núcleo espacial donde se cambia el espacio y creo que, la percepción del tiempo. Si es verdad que en ellos, en sus plantas bajas, he querido ofertar a la ciudad un espacio para encuentros más especializados.

El acto de construir ha perdido su prestigio y lo denunciabas "avant la lettre" cuando afirmabas sus excesos. ¿Cómo se lo devolvemos, si es que debemos hacerlo?

Si perder prestigio significa que hoy parece que interesa poco, entonces tienes razón. Pero yo creo que lo pierde cuando el construir se transforma en un acto irracional o depredador del medio natural o destructor de los espacios de vida, sea en la ciudad o en el territorio.

Por el contrario, yo creo que construir es la expresión más genuina de la acción de crear. Me siguen interesando la razón y la poética constructiva como uno de los soportes de la arquitectura. Algunas veces percibirlo me emociona profundamente. Creo que en momentos de confusión, cuando parece que todo vale, recordar que cada forma, es decir, su construcción, supone un proceso de ordenar la materia, ensamblarla, transformarla para hacer determinado lo que aún no lo es, venciendo limitaciones, da claridad y nos hace ver lo consustancial que es con la arquitectura.

Tal vez, como has señalado en alguna ocasión, el proyecto indica el guión de su construcción dejándolo incompleto para provocar huecos a su interpretacion. ¿La experiencia de Paderne fue satisfactoria? ¿La consideras hoy reproducible? El recurso a la traza curva ¿fue un intento de controlar el procedimiento?

Las viviendas de Paderne supusieron un intento nada frecuente de enfrentarse con la construcción de viviendas en el medio rural gallego, donde la dispersión y el minifundio van salpicando de construcciones individuales el territorio.

Se proyectaron 15 viviendas, equipamientos sociales, infraestructuras y urbanización, todo ello conjuntamente valorando los espacios públicos de convivencia, y pensando que rando los espacios públicos de convivencia, y pensando que rurales podían sugerir una organización en la implantación que rurales podian sugerir una organización en la implantación que pero dentro de un conjunto construido y de un proyecto único. pe experiencia se completaba con la autoconstrucción de los principales elementos comunes, con la posibilidad de utilización de energías renovables. De esto hace 30 años. La trama proyectada fijó los elementos que definían el espacio público, y pensé que al descender al detalle debería permitir que apareciera lo aleatorio.

Creo que la relación entre un buen discípulo y su maestro parte de que cada uno debe conservar su personalidad. Sus arquitecturas no tienen por qué parecerse en sus apariencias, puede ser que se parezcan en sus enfoques y actitudes.

La experiencia de Paderne fue arriesgada, como toda aventura, pero no totalmente satisfactoria porque hubo un momento en que se torció, y los márgenes de libertad que yo establecía no se entendieron y se sobrepasaron. La experiencia fue muy ambiciosa y para

No sé explicar bien el por qué de las trazas curvas, creo que fue algo intuido. Eran parte de la estructura de referencias filas de la trama que proyectaba. Eran el núcleo central del espacio de la planta baja, el resto era una estructura ligera que soportaba lo accidental que se iba añadiendo, que podía nacer apoyado en los muros. Se intentaba ordenar las acciones imprevistas: arrimos de pequeñas dependencias, plantación de parras, etc., entonces estos muros se transformaban en separadores espaciales de las viviendas.

Puede ser que tengas razón y también fuese un intento de controlar el procedimiento, de conservar la presencia de lo proyectado. No lo sé.
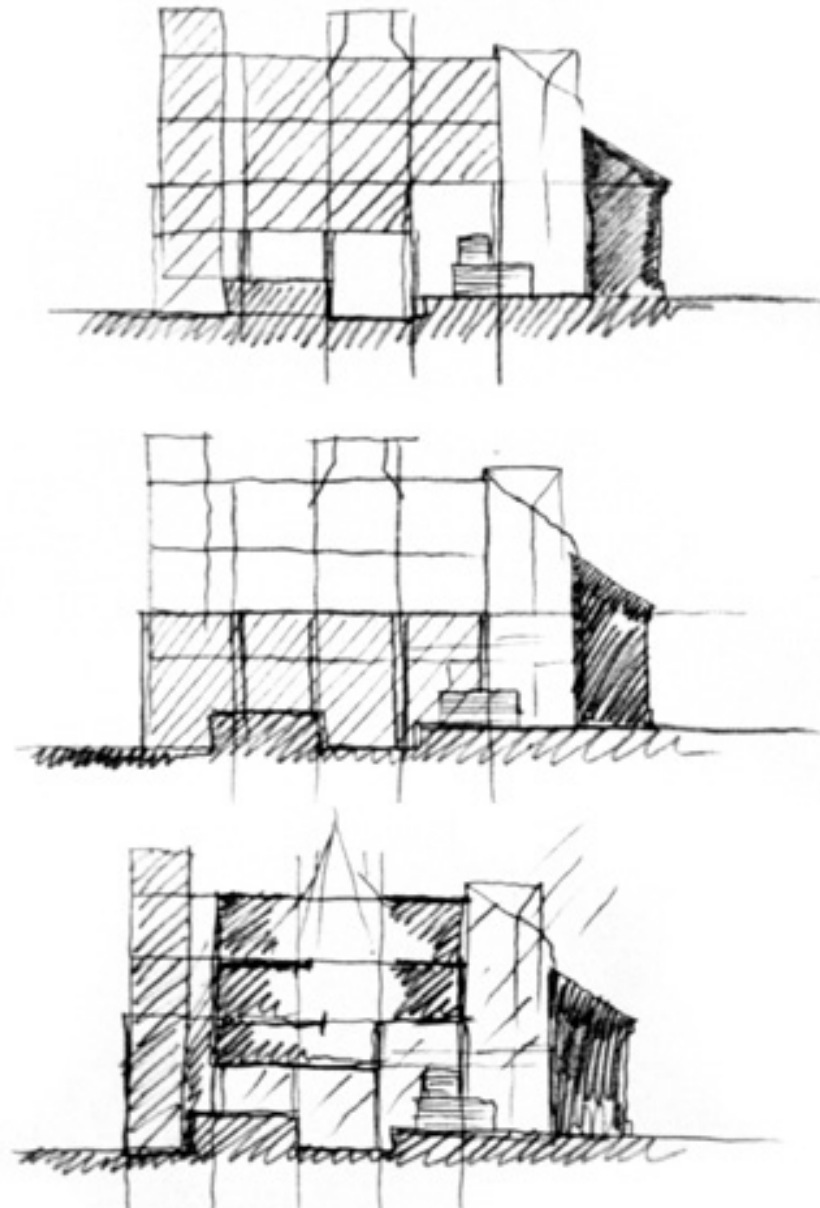

Museo de Bellas Artes de A Coruña, 1988-95

Lo que he pretendido es buscary entender las razones de la necesidad de la arquitectura que me encargan, entender para qué es necesaria, si lo es. Cuando lo es, me parece que el proyecto se llena de fuerza, con independencia de la componente creativa, poética y personal que pueda existir, que naturalmente es fundamental.

Esta idea de lo inacabado, ¿es la versión más explícita de la ambigüedad, o la difusión del límite que en alguna ocasión has señalado?

Es una reflexión sobre el papel del arquitecto

Siempre me ha interesado el uso que se hace de la arquitectura como función y como vivencia. Me parece un tema muy importante el de los límites entre facilitar el uso y las imposiciones que hacemos, exigidas por la arquitectura que nos interesa. En ciertas arquitecturas estas relaciones se tensan.

Me gusta pensar espacios con un orden capaz de generar posibilidades diversas al que los usa, provocando espacios abiertos a múltiples interpretaciones y, a veces, usos.

Me desagrada aquella arquitectura que con el uso se estropea, que no lo resiste, que sólo admite la foto antes de usarse. Esta arquitectura me parece banal y que está muerta.

Esta característica, la ambigüedad de los límites, la multiplicidad de lecturas incluso contradictorias del proyecto ¿podríamos entenderla como un nexo de tu lectura de Galicia con el mediterráneo? ¿Un nexo entre Pantelería, de Tusquets y Clotet, al que entrevistamos en el número 1 de la revista, y tu casa de Veigue?

La casa de Veigue me la encarga un amigo médico. Es una vivienda de segunda residencia y en el encargo se insistió en dos cosas: que se cuidase la seguridad, y que no tuviera un jardín que le obligase a pasarse el fin de semana trabajando. Y anadio que le gustaría que la casa fuese de piedra.

Estos requerimientos explican por qué existe un núcleo central fácil de cerrar, perfectamente controlable, y cómo éste se puede ampliar hacia dependencias ligeras como invernaderos o galerías añadidas, que casi se confunden con el exterior denso que se Esta idea la aproveché para hacer un espacio denso que se va aligerando hacia el exterior, perdiendo masa hasta quedar en nada. Era como trabajar sobre los espacios de transición, tan importantes en la arquitectura, creando un entorno como una infraestructura de posibilidades donde se superponia la pergola con su vegetación y la galería no siempre de crea lugares gratos era muy ampla. La idea me atrajo la materialización no me desagradó con ese aire impersonal y desmaterializacion

Quise dejar patente el deseo del propietario dejando ver esa oluntad de envolverla en piedra, lo hice con mármol.

Hay algo que es importante después de hacer la casa, la amistad con mi amigo médico se aumentó.

Tu descripción de las casas de la Alcudia es emocionante. ¿Emoción y razón son los dos ingredientes de tu arquitectura?

Creo que sí aunque no me atrevo a simplificar tanto, porque también es un tema de intuición, sensibilidad, diversión. Es todo muy complejo y luchas como puedes para que todo encaje además está la suerte, que siempre juega un papel. 
Tu arquitectura se puede leer desde conceptos encontrados. ¿Solidez y ligereza, antiguo y nuevo, piedra y aluminio, rigor y libertad, industrialización y oficio?

Puede ser, quizás ocurre con casi toda la arquitectura.

De todos modos siempre me interesa que permita varias lecturas, que pueda tener varios significados cruzados. Me parece que cuando esto ocurre, gana densidad. Me gusta ver cómo una a otra Suele locurrir que, cuando tengo una idea o dución, estoy muy proxino ción, estoy muy próximo a la opuesta. Este transito me interesa hastana, ś́lo veo lecision, entonces es como si abriera una se pasa bien. Seguramente a todos nos ocurre algo parecido.

\section{¿Los límites entre ellos son tan nítidos?}

Yo creo que no. Ocurre además que muchos son producto de intuiciones. Desde cada uno de los conceptos, cuando te metes en él, entiendes los otros. Todos son visiones cruzadas de un mismo tema, la arquitectura.

Incluso en los propios mecanismos del proyecto. Algún proyecto como el museo de A Coruña o la casa de la cultura de Chantada, ¿se podría entender como la relación tensa entre una cota cero táctil, casi telúrica y una cubierta ligera y con su propio movimiento?

Podría ser, pero me parece que más en Chantada. Aunque también tiene otra lectura. La cota cero es el suelo, continuidad de la plaza, el espacio público. Sobre él se acota un nuevo espacio con una cubierta que arropa un nuevo ambiente distinto, creando una atmósfera que nos induce a otra forma de estar y sentir. Como los perímetros no son exactamente coincidentes, con la luz y los materiales consigues que los límites sean más ricos.

¿Entremedias un espacio complejo inaprensible geométricamente y cualificado por la luz?

Opino que cuando existe el carácter de espacio público, la luz debe de ser móvil, cambiando con la posición del sol. Creo que un rayo de sol cambia el espacio. Cada arquitectura debería que un rayo de sol cambia

La complejidad del espacio debe manifestarse por la diversidad de descubrimientos que uno se va encontrando. La arquitectura se puede entender definida por la luz, que le ayuda a construir el espacio, lo pone en valor.

Otra cosa es su claridad interior. Hay algunas arquitecturas que tienen algo que podemos llamar claridad, que es muy importante. Es como si irradiasen luminosidad, y no tiene que ver con el sentido literal del término. Son claras y luminosas en su expresión, y hacen que otras a su lado parezcan confusas y apagadas.

La contraposición de esa espacialidad interior con el exterior en proyectos como el mercado de Santa Lucía con un estricto exterior industrializado podía ser otra de con dualida extras Clichy, ¿fue una referencia consciente?

No, no fue una referencia, de hecho aún no la había visto, a pesar de que J. Prouve me interesó desde que trabajé con de la Sota, era tema de muchas conversaciones. Después he conocido su obra e incluso llegué a trabajar en unos pabellones que tenía en la Ville Nouvelle de la Vallé de la Marne.

Yo creo que construir es la expresión más genuina de la acción de crear. Me siguen interesando la razón y la poética constructiva como uno de los soportes de la arquitectura. Algunas veces, percibirlo me emociona profundamente.

La trama estructural tiene mucha presencia en tus dibujos. Frente a su cuidado dibujo que llega a la expresión constructiva en proyectos como los de Chantada o A Coruña, ¿es posible que en tus proyectos más recientes tenga por el contrario menos apariencia?

No lo había pensado y podría decirse de algunos de los proyectos realizados últimamente.

Pero los últimos años he hecho muchos proyectos que no se han construido ni publicado, en ellos la trama estructural sigue estando encardinada a la idea del proyecto. Concurso Ciudad de la Cultura, Parque Artabria, Museo Masso, equipamientos del Campus de Ourense, Museo del papel, etc. Es posible que en los últimos sean tramas más dinámicas, como si reflejasen procesos, tránsitos de una cosa a otra.

Perímetro y centro. Te imaginamos disfrutando construyendo la colina y el paisaje de Santiago, los recorridos, el tiempo y tus recuerdos, alrededor de la casa del presidente de la Xunta. Discernir lo relevante del proyecto, su estrategia y su perímetro, las secuencias de lo doméstico, ¿sería tal vez la mejor ambición de este proyecto?

Bajo su apariencia tranquila es un proyecto complejo lleno de tensiones, muchas derivadas de su propio enunciado. Su argumento: una vivienda para usar diferentes personas desconocidas donde lo único que les une es el cargo y donde los problemas de seguridad se enfrentan a la necesaria privacidad que tatividad al que intento dar la vuelta, y hacer del distanciamiento del poder el intento dar la vuelta, y hacer del distanciamiento del poder el acercamiento a sentirse representado en el lugar, y todo ello pensando en los diferentes grados de privacidad de los espacios. Entre lo público y lo privado se establece un gradiante de posibilidades que me parece de interés, y se acrecenta si se hace reversible y variable en su uso.

Para mí el máximo interés ha radicado en hacer una arquitectura casi sin geometría, una arquitectura de lo próximo, el muro, el pavimento, la vegetación. Basada en la convivencia de pequeños elementos que articulan espacios con forma difícil de precisar, arquitectura de lo inmediato. Ello supone entender e espacio formado por reductos potenciales que yo voy recreando de pequeños lugares de estancia. Arquitectura para estructura grafiada. Arquitectura diluida en la colina.

Me gusta pensar espacios con un orden capaz de generar posibilidades diversas al que los interpretaciones $y$, a veces, a diferentes usos.

Tu etapa más reciente ahonda más bien en la dualidad entre arquitectura y naturaleza. ¿Te gustaría que tu arquitectura fuera tan natural como un árbol?

Sí, ello supondría que está viva. No me refiero a que se confunda con el mundo natural, sino a que posea la energía interna quier de darle la indepe

En Santiago, en Veigue, la naturaleza invasiva trabaja en esa dirección. En la piscina de Chantada, tal vez lo hacen su posición y su estrategia. La construcción natural y escalada a lugar se expresa por el contrario de manera kahniana. ¿La
arquitectura vuelve a estar en esta tensión entre naturaleza y expresión constructiva?

Creo que hoy la naturaleza está prácticamente controlada, manipulada y, en gran medida, construida. El concepto de lo natural varía con la época. Hacemos arquitectura con los árboles, construimos y creamos espacios con ellos. En realidad los cultivos ya son órdenes impuestos por el hombre en la naturaleza. Me interesan los límites variables entre lo natural y lo construido artificialemente, así como sus relaciones. Desde la arqui-
tectura realizada con elementos naturales, por ejemplo constructectura realizada con elementos naturales, por ejemplo construcciones con lo vegetal, hasta aquella cuya materia se fracciona y pe deshace en la naturaleza. En esa relación y en esa tensión me encima está la calidad de la arquitectura.

¿Cómo imaginarías el oficio de arquitecto en un contexto sin artesanía? ¿Cómo harías las barandillas?

as haría escogiendo y utilizando lo que ya está hecho.

En realidad antes de hacer algo siempre sopeso las posibilidades que tengo. A veces la existencia de un artesano, un obrero que sepa hacerlo, condiciona el camino. En caso contrario intento utilizar bien lo que me ofrece la industria. Siempre es un tema de decisiones, por eso me gustan los sistemas industriales abiertos que permiten ciertas correcciones, casi como bricolaje.

En tus proyectos ¿trabajas a partir de la manipulación del catálogo o empiezas desde cero?

Utilizo los dos caminos a la vez, nunca intento inventar algo que ya está hecho y que me satisface, solamente invento cuando pienso que se puede hacer mejor y más barato. Por tanto todo
depende de la escala del tema y de lo específico y determinado del problema.

\section{¿Consideras que la obra es un terreno donde el proyecto se} puede reformular?

Todo sabemos que, lógicamente, un cambio es un problema en la marcha de la obra. No es deseable hacerlo salvo si es estrictamente necesario para adaptarlo a cambios imprevistos
impuestos o, como ocurre a veces, para solucionar errores.

Resulta curioso pensar que la obra es la única industria cuyos diseños se confían en general a una muestra in situ, sin más pruebas. En la ejecución de una obra surge a veces el deseo de afinar el diseño, el color, de precisar detalles que se personalizan en sitios concretos y por tanto muy difíciles de prever; esto exige una mirada muy atenta a su ejecución sólo posible en ciertas arquitecturas. El resto, lógicamente, tiende a la industrialización y al montaje, que se está independizando cada vez más de la mirada del arquitecto. ¿Siempre es posible lo doméstico en la arquitectura, en el
sentido amplio que implica una proximidad con el usuario?

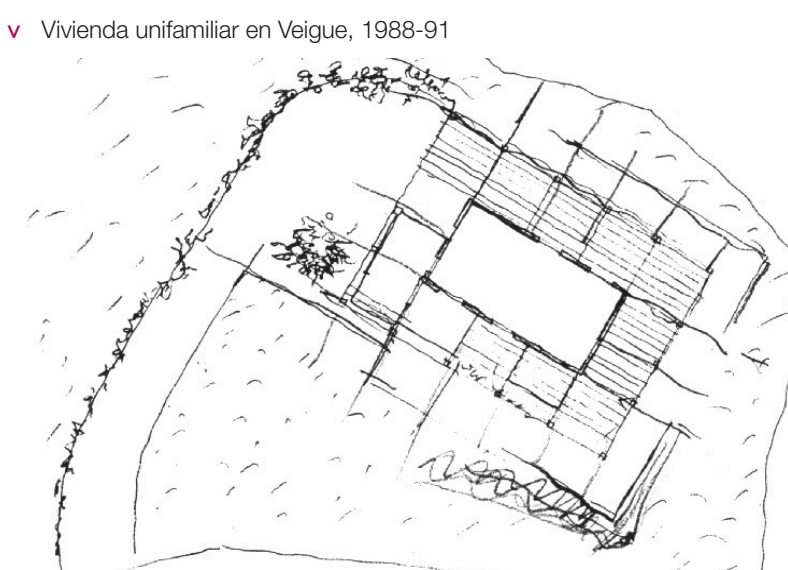

No. Lo doméstico puede inducir a error. Cuando ocurre es inconvenientes, y creo que éstos últimos pueden ser más.

Qué actitud has tomado como arquitecto cuando te has construido casas para ti mismo?

He pensado aprovechar la ocasión para plantear algo que difícil hacérselo a otro, es decir probar algo, alguna idea. Por otra parte, me interesa pensar que la casa con pequeñas modificaciones puede servir para otros usuarios.

Ello supone una actitud y un punto de partida conceptual.

¿Qué papel juegan tus dibujos en el proceso del proyecto?

Son anotaciones, con ello me explico mejor a mi mismo, me ayudan a conocer. Además me sirve para que otros me entien dan mejor.

Tus dibujos son producto de la inteligencia tal y como la entendía de la Sota. Su belleza, ¿añade una aspiración a las emociones?

En cierto modo los dibujos lo incorporan todo en sí mismos. De la Sota hacía dibujos muy sensibles, son los que el queseparadas las cosas.

Yo hago lo que puedo, no sé calificarlo, me gusta que expresen ideas y sensaciones que espero lograr. Otras veces, son deogramas como descripciones condensadas de alguna idea, todo depende de la etapa del proyecto que representan.

Cómo funciona tu despacho? ¿Dibujáis en CAD? ¿Consuís maquetas?

Mi despacho es pequeño. Naturalmente dibujamos con CAD y hacemos maquetas, creo que como todos, pero solamente después de pensar, dibujar ideas, hablar y hacer algún croquis. Las primeras maquetas son casi croquis.

En el trabajo no nos apoyamos en revistas ni libros, y si lo hacemos alguna vez es cuando el proyecto está ya vencido. De hecho los libros del estudio son casi todos técnicos.

esde tu labor académica y como participante en numerosos urados de concursos, ¿qué salidas ves hoy a la profesión?

No las veo claras. Racionalmente soy pesimista, no me gusan muchas de las cosas de nuestra época que condicionan y envuelven la arquitectura. Entiendo que va a ser otra cosa y que necesita reformularse en su relación con la práctica profesional y, aturalmente, con los colegios de arquitectos.

A pesar de ello, visceralmente soy optimista y aún creo que hay cabida para el arquitecto, o para la profesión sustituya a la que era, que desee decir o crear algo, quizás con otra organización, con otros medios.

n la pregunta que suele cerrar nuestras entrevistas, ¿que Coruña?

No me lo he planteado nunca, no lo he pensado.

Recuerdo que una vez un grupo de arquitectos nos reunimos con de la Sota. Nos había llamado para comentar un Máste que iba a dirigir y dijo: el primer objetivo es "desaprender".

Ponía en evidencia que en la enseñanza de la arquitectura hay materias técnicas y conceptuales objetivas que se pueden enseñar y otras, las más creativas como los proyectos, donde la mbjetividad es muy importante.

Si a esto añadimos el variado panorama de la arquitectura hoy, y la incertidumbre de una crisis que algunos deseamos que cambie aún más las cosas, el lío está servido.

Por tanto, en principio sería prudente e introduciría ciertas condiciones, casi elementales, sobre los temas que creo que ya han demostrado que exigen reflexión, tales como la utilización de la información, a ello le prestaría especial atención. Otro tema ería la necesidad de que la escuela se abra más a la sociedad aciéndola presente en los problemas sociales y urbanos, y todo ello a través de reflexiones críticas. Insistir en ser críticos me paimportante.

Creo que cuando se dice que el eje de la carrera de arquitectura es el proyecto, debería también significar que todas las asignaturas se apoyan en la imaginación y en la creatividad. Desde cualquiler asignatura se puede dar una clase de arquitectura, de hecho puede ser más cómodo e igual de eficaz. Pero creo que en los conocimientos técnicos y conceptuales hay que uscar el rigor y la eficacia.

La enseñanza de proyectos, la clase, pienso que debería centrarse más en el rigor crítico y en educar la sensibilidad. La clase es en cierto modo un soporte para que el alumno sea más bre para que, si quiere o puede, busque y se busque.

Como ves, vaguedades y generalidades básicas, no hablo de estrategias, planes ni programas, que a lo mejor es lo que interesa.

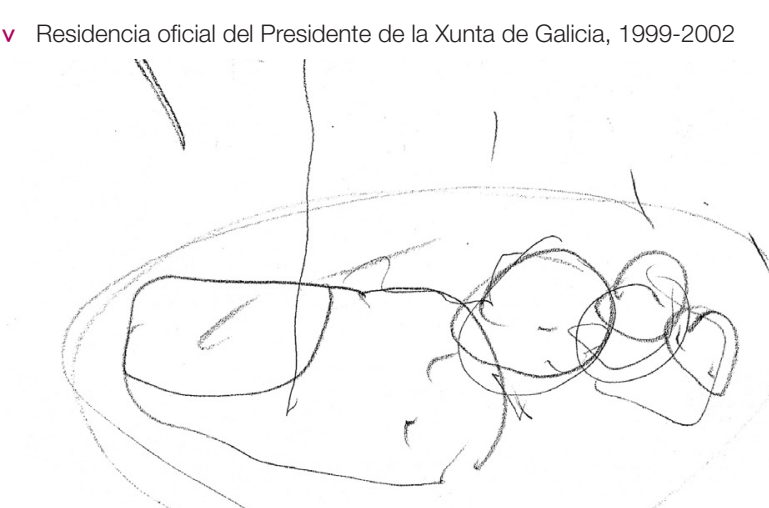

